\title{
La discapacidad en los medios de comunicación: los Juegos Paralímpicos de Londres 2012
}

\author{
Mayra Rivarola \\ Universidad Rey Juan Carlos, España \\ Graduada en periodismo por la Kansas State University \\ y Master de Periodismo de Agencia \\ Raquel Rodríguez Díaz \\ Universidad Rey Juan Carlos, España \\ Profesora Titular del área de Periodismo \\ Universidad Rey Juan Carlos
}

\section{Palabras clave}

Deshabilidad agenda de medios

lenguaje

deportes

olímpicas

y paralímpicas

\section{Resumen}

Este estudio pretende reflejar que las personas con discapacidad no ocupan presencia informativa en la agenda de los medios al mismo tiempo que el uso del lenguaje que se emplea para referirse al colectivo no es el adecuado. Como caso de estudio se ha analizado la cobertura que realizaron los medios de comunicación españoles durante los Juegos Olímpicos y Paralímpicos de Londres 2012. Se realizó un análisis de contenido de tres medios escritos con amplia difusión, al tiempo que diversos entre ellos: uno especializado (Marca), un generalista (El País) y una agencia de noticias (Agencia EFE). El estudio muestra que existió una gran diferencia entre el número de informaciones publicadas sobre ambos eventos: 3.767 noticias de los Olímpicos y 245 noticias de los Paralímpicos. Por otro lado, y pese a las hipótesis planteadas, se identificó que en la mayor parte de las noticias el lenguaje utilizado para referirse a las personas con discapacidad es adecuado, en base a criterios de las guías de estilo sobre discapacidad. 


\section{The absence of disability in mass media: the London 2012 Paralympic Games}

\begin{tabular}{l}
\hline Keywords \\
\hline \\
Disability \\
media agenda \\
language \\
sports \\
olympics and \\
paralympics
\end{tabular}

\section{Cómo citar el artículo}

Rivarola, M. y Rodríguez Díaz, R. (2015). La discapacidad en los medios de comunicación: los Juegos Paralímpicos de Londres 2012. Revista de Comunicación y Salud, Vol. 5, pp. 129-147.

DOI: http://doi.org/10.35669/revistadecomunicacionysalud.2015.5.129-147

\begin{abstract}
This study seeks to reflect that people with disabilities are absent in the media agenda and to determine that the language used to refer to this group is not adequate. As a case study, the coverage that the Spanish media dedicated to the London 2012 Olympics and Paralympics was analyzed, along with a content analysis of the articles dedicated to the Paralympics. Three written media with wide distribution and diverse content were analyzed: a specialized magazine (Marca), a generalist newspaper (El País) and a news agency (EFE). The study shows a wide gap between the number of articles published on both events: 3,767 articles for the Olympics and 245 for the Paralympics. On the other hand, and despite the original hypothesis identified, most of the language used to refer to people with disabilities was adequate, based on recent and international standards.
\end{abstract}




\section{Introducción}

El 15 por ciento de la población en el mundo tiene algún tipo de discapacidad y la mayor parte las personas tendrán algún tipo de discapacidad permanente 0 transitoria a lo largo de sus vidas (OMS, 2011). En España, la cifra de personas con discapacidad se sitúa entre el 8,5 y 10 por ciento (INE, 2008). A nivel mundial, las personas con discapacidad tienen los peores resultados en cuanto al acceso a la salud y a la educación, además de las tasas de pobreza más altas que el de las personas sin discapacidad. Esto se debe en parte a los obstáculos impuestos por la sociedad, tanto físicos como actitudinales (OMS, 2011).

Pese a estos datos y a los esfuerzos de organizaciones locales, nacionales e internacionales que promueven los derechos de las personas con discapacidad, varios investigadores y autores han identificado y alertado sobre una cobertura escasa, inadecuada y en su mayoría negativamente estereotipada que otorgan los medios de comunicación a todo lo relacionado con este colectivo (Del Río, 1986; Biklen y Bogdan, 1977; Day, 2002; Agencia Global de Noticias, 2010).

Una iniciativa que intenta reducir la exclusión de este colectivo, en especial de los medios de prensa, es el movimiento paralímpico (CPI, 2012a). El presidente del Comité Paralímpico Español (CPE), Miguel Carballeda Piñeiro, expresó: "Los Juegos Paralímpicos son el gran escaparate mundial en el que los deportistas con discapacidad, y por extensión, las personas con discapacidad en general, muestran cada cuatro años la grandeza del ser humano, las posibilidades que tenemos las personas de desarrollar al máximo nuestras capacidades" (Solves, 2013: 15). Los Paralímpicos, además de destacar el alto desempeño deportivo de los atletas, tienen la función normalizadora de la discapacidad, lo que a su vez fomenta la inclusión de estas personas en la sociedad (Solves, 2013; CPI, 2012b).

En su discurso de clausura de los Paralímpicos de Londres 2012, el presidente del Comité Paralímpico Internacional (CPI), Philip Craven, aseguró que el evento tuvo un impacto significativo en la sociedad británica. Uno de cada tres adultos británicos cambió su actitud hacia las personas con discapacidad después de ver los Juegos, mientras ocho de cada diez pensaron que los Juegos influyen positivamente en la forma que las personas con discapacidad son vistas por el público. El 65 por ciento de los encuestados consideró que los Juegos representan un gran avance en la protección de los derechos de las personas con discapacidad (CPI, 2012b). Los Juegos Paralímpicos de Londres 2012 y su cobertura en los medios de comunicación lograron influir positivamente en las actitudes de la audiencia hacia las personas con discapacidad, al menos al corto plazo (Ferrara, 2015).

Un análisis de las actitudes hacia las personas con discapacidad de espectadores, voluntarios y miembros de la comunidad demostró que la exposición a los Juegos de la Mancomunidad, celebrados en el 2014 en Escocia, está asociada con una actitud positiva hacia la discapacidad (Paradis et al, 2014). Por otro lado, un análisis cualitativo de los discursos de atletas brasileños muestra que la atención mediática en los deportes adaptados es un factor importante para la práctica del deporte y la expectativa de carrera 
profesional, ya que influencia sus posibilidades de inclusión social y ganancias financieras (Rodrigues et al, 2014)

Sin embargo, estos esfuerzos quedan estancados cuando no reciben cobertura mediática. Los medios de comunicación cumplen un rol fundamental para superar las barreras que excluyen a las personas con discapacidad (Declaración de Salamanca, 2004). La exclusión de la agenda de los medios de los Juegos Paralímpicos y en general de las personas de este colectivo tiene graves repercusiones, considerando la influencia que tienen la agenda de los medios en la agenda pública y política (Solves, 2013).

Un análisis del contenido de los principales diarios estadounidenses recogió un promedio de 427 artículos por medio dedicados a los Olímpicos de invierno llevados a cabo en Salt Lake City en el 2002, mientras que los medios sólo dedicaron un promedio de dos artículos a los Paralímpicos que tuvieron lugar en la misma ciudad pocos días después (Golden, 2003). Tynedal y Wolbring (2013) analizaron la cobertura de los Paralímpicos en el New York Times (NYT) desde la primera aparición de los Juegos en 1955 hasta el 2012 y evidenciaron que la cobertura otorgada era mínima y a menudo retrataba a los atletas paralímpicos de manera estereotipada.

En el caso español, varios investigadores (Solves, 2012) analizaron la cobertura de medios españoles de los Juegos Paralímpicos Beijing 2008 llegando a la conclusión que los medios ofrecieron una visión "integradora" del evento, es decir, que no tendieron a destacar el hecho de la discapacidad, ni en el uso del lenguaje ni en el tratamiento de las imágenes. Sin embargo, el estudio consideró que la mayoría de los medios - con excepción de los medios especializados en deportes y la Televisión Española - no otorgó una cobertura apropiada (Solves, 2013).

La agenda de los medios de comunicación desempeña un lugar central dentro de los procesos cognitivos que tienen los individuos a la hora de interpretar cuáles son los temas más importantes en la sociedad. Los estudios de agenda setting (McCombs y Shaw, 1972; McCombs, 1996; Dearing y Rogers, 1996), reflejan que los medios establecen cuáles son los temas de mayor relevancia informativa, ofreciendo una mayor cobertura de estos. Como consecuencia de esta función de la fijación de los temas más importantes en la agenda mediática, los lectores, la audiencia en general, aprenderán de la prensa a destacar esos mismos temas en la agenda pública, pudiendo convertirse en temas de opinión y debate.

"La prensa no tiene mucho éxito en decir a la gente qué tiene que pensar pero sí lo tiene en decir a sus lectores sobre qué tienen que pensar" (Cohen, 1963: 13). Con este enunciado se expresa la diferencia entre la relevancia que tienen los medios en determinar los marcos cognitivos relativos a los temas informativos. Numerosos estudios realizados en diferentes décadas reflejan que la prensa desempeña una función trascendental a la hora proponer temas al público. A mayor número de noticias relativas a un tema, mayor importancia de ese tema en la agenda de los ciudadanos (McCombs, 2004; lyengar y Kinder, 1987; Krane, 2010; López-Escobar et al., 1996; Rodríguez, 2004; Rubio, 2014). 
Desde esta perspectiva de agenda, planteamos que la visibilidad o invisibilidad informativa que tienen los medios de comunicación con las personas discapacitadas determina su imagen pública. Diferentes autores han trabajado la importante combinación del binomio medios y discapacidad y su representación en la prensa (Pappous et al, 2009; Rius et al, 2010). En el ámbito del deporte, la discapacidad ha sido objeto de análisis de contenido mediático igualmente (Sánchez y Mercado, 2011; Álvarez y Mercado, 2015; Leary, 2011). Resultados de estas investigaciones expresan que, a medida que pasa el tiempo, los medios abordan más y con mayor corrección la discapacidad, pese a tener aún poca visibilidad en la prensa.

Por otro lado, durante los años noventa organizaciones internacionales - como la Organización de Naciones Unidas (ONU) - iniciaron esfuerzos para cambiar el uso del lenguaje que se empleaba para referirse a las personas con discapacidad (Solves, 2013). En 1982 la Asamblea General de la ONU aprobó el Programa de Acción Mundial para las Personas con Discapacidad, que en su enunciado número 149 detalla que los medios de comunicación deben desarrollar pautas para mostrar "una imagen comprensiva y exacta" sobre este sector (ONU, 1988). En la Convención sobre los Derechos de las Personas con Discapacidad y Protocolo Facultativo de la ONU aprobado en el 2006 y ratificado por el Gobierno español en 2008 se adopta el uso de este lenguaje.

En 2002 un grupo de 400 expertos internacionales participó en el Congreso Europeo de las Personas con Discapacidad, aprobando la Declaración de Madrid. En su artículo 6, el documento resalta lo siguiente: "Al referirse a cuestiones de discapacidad, los medios de comunicación deberían evitar enfoques de condescendencia o humillantes y centrarse más bien en las barreras a las que se enfrentan las personas con discapacidad y en la positiva contribución que las personas con discapacidad pueden hacer una vez que se eliminen esas barreras" (Declaración de Madrid, 2002: 7).

En el 2004, periodistas españoles reconocieron la importancia del lenguaje que se utiliza en los medios de comunicación para luchar contra estereotipos que impiden a las personas con discapacidad integrarse en la sociedad como ciudadanos en igualdad de condiciones (Declaración de Salamanca, 2004). "El lenguaje es una construcción social e histórica que influye en nuestra percepción de la realidad, condiciona nuestro pensamiento y determina nuestra visión del mundo", señala Fernández (2006: 19).

En las últimas décadas los términos comúnmente utilizados como "minusválidos" o "deficientes" se sustituyeron, primero, por la expresión "personas minusválidas", y después por "personas con discapacidad", que eludía las connotaciones peyorativas de un término que significaba "menosválidos" (Solves, 2013).

José Luis Fernández (2006), en su Guía de Estilo sobre Discapacidad para Profesionales de los Medios de Comunicación, define y recoge los vocablos erróneos y con connotaciones negativas que no deben utilizarse como puedan ser: anormal, deficiente, disminuido, impedido, incapacitado, inválido, lisiado, minusválido entre otros. El trabajo expuesto por Fernández considera que estos términos deben reemplazarse con el término "persona con discapacidad", 
para dar énfasis en la persona y no en la discapacidad, por ejemplo "persona sorda" o "persona con Alzheimer" entre otros. Se recomienda evitar el uso de verbos negativos como "sufrir" o "padecer", así como expresiones negativas como "afligido por", "afectado por", "víctima de", y sustituirlos por verbos neutrales como "tener". Entre otros ejemplos de recomendación figuran evitar la expresión "postrado" y sustituirla por "utiliza silla de ruedas" o "está en una cama".

Pese al esfuerzo por generar guías de estilo sobre el lenguaje y un mejor uso de los conceptos en la prensa, el artículo publicado por Solves (2013) y que lleva por título "SOS Discapacidad: los discursos de la discapacidad en los medios españoles" encontró que los intentos de modificar el lenguaje no han sido exitosos en España.

Si bien el deporte adaptado para personas con discapacidad existía con anterioridad (Chevalley, 2011), los primeros Juegos Paralímpicos de verano, donde compitieron 400 atletas de 23 países, se llevaron a cabo en 1960 en Roma, Italia (COI, 2011b). Los Juegos Olímpicos de verano analizados en este estudio se llevaron a cabo desde el 27 de julio hasta el 12 de agosto del 2012 en Londres. Un total de 10.568 atletas de 204 países compitieron en 26 deportes, incluyendo 39 disciplinas, según datos oficiales del Comité Olímpico Internacional (COI). Alrededor de 21.000 periodistas fueron acreditados, representando una audiencia potencial de cuatro mil millones de personas, según estimaciones del COI. Cerca de 70.000 voluntarios participaron en la organización de las 302 competencias, que se llevaron a cabo en 34 instalaciones distribuidas en el Parque Olímpico de Londres.

Pocos días después - del 30 de agosto al 9 de setiembre - y en el mismo sitio, iniciaron los Paralímpicos, competencia que involucra a atletas con seis grupos diferentes de discapacidad: amputado, parálisis cerebral, discapacidad visual, lesiones de la médula, discapacidad intelectual y un grupo que incluye a todos aquellos que no encajan en los grupos antes mencionados. Este evento reunió a 4.237 atletas de 164 países compitieron en 20 deportes (CPI, 2012a). Un total de 1.950 periodistas fueron acreditados para cubrir el evento, estimándose que la audiencia potencial alcanzó a 2.7 millones de espectadores (CPI, 2012b).

Tabla №1: Resumen de Olímpicos y Paralímpicos de Londres 2012

\begin{tabular}{|l|l|l|}
\hline & Olímpicos & Paralímpicos \\
\hline Atletas & 10.568 & 4.237 \\
\hline Países & 204 & 164 \\
\hline Deportes periodistas & 21.000 & 20 \\
\hline Competencias de & 26 & 503 \\
\hline $\begin{array}{l}\text { Número } \\
\text { acreditados }\end{array}$ & 302 & \\
\hline
\end{tabular}




\begin{tabular}{|l|l|l|}
\hline Audiencia potencial estimada & $\begin{array}{l}4.000 .000 .00 \\
0\end{array}$ & 2.700 .000 \\
& & \\
\hline
\end{tabular}

Fuente: Elaboración propia en base a datos del COI y el CPI.

\section{Objetivos e hipótesis de investigación}

El planteamiento de este estudio busca analizar si las personas con discapacidad están fuera de la agenda de los medios, a través del estudio de la cobertura informativa que tuvo la prensa española durante los Juegos Olímpicos y Paralímpicos celebrados en la ciudad de Londres en el año 2012. Se busca identificar si en España se han adaptado a los estándares de lenguaje aceptados internacionalmente como adecuados para referirse a este colectivo.

Para observar la invisibilidad de las personas con discapacidad en los medios, se considera ilustrativo comparar la cobertura que se dedicó a los Juegos Olímpicos de Londres 2012 con aquella otorgada a los Paralímpicos, que tuvo lugar en el mismo lugar unos días después. Si bien es lógico que estos Juegos reciben menos atención mediática, por su reciente historia y su envergadura, se analizó la proporción entre el nivel de cobertura al número de atletas participantes. Para identificar si existe un aumento del interés mediático en los Paralímpicos se decidió contabilizar la cobertura de los anteriores tres Juegos Paralímpicos, Pekín 2008, Atenas 2004 y Sídney 2000 en uno de los medios de prensa analizados.

Posteriormente, se analizó el lenguaje utilizado en las noticias dedicadas a los Paralímpicos del 2012 para determinar si éste se adecua a los estándares establecidos por organismos nacionales e internacionales, en específico por la guía de estilo mencionada anteriormente. A ello se sumó la identificación de los principales enfoques utilizados en las noticias.

Las hipótesis planteadas fueron las siguientes:

1) Los medios escritos españoles otorgaron una escasa cobertura a los Juegos Paralímpicos de Londres 2012, en comparación con la cobertura dedicada a los Olímpicos, pese a que hay un incremento mediático a lo largo del tiempo.

2) La cobertura dedicada a los Paralímpicos fue en su mayoría inadecuada, en cuanto al uso del lenguaje, de acuerdo a los estándares establecidos en guías de estilo.

\section{Metodología de investigación}

El análisis de contenido se realizó en tres medios escritos de amplia difusión en España: la versión impresa de un medio generalista (El País), la versión impresa de un medio especializado (Marca) y una agencia de noticia (Agencia $E F E)$ y la fecha de realización de dicho análisis fue la de los dos eventos deportivos. Considerando que los medios impresos publican las noticias con un 
día de retraso, se escogieron las siguientes fechas: del 27 de julio al 13 de agosto (Olímpicos) y del 29 de agosto al 10 de setiembre (Paralímpicos).

Debido a que la Agencia EFE fue la que publicó un mayor número de notas dedicadas a los Paralímpicos de Londres 2012, se contabilizaron las notas publicadas en referencia a los Paralímpicos de Pekín 2008 (del 6 al 17 de setiembre), Atenas 2004 (del 17 al 28 de setiembre) y Sídney 2000 (del 18 al 19 de octubre), con el fin de conocer si la cobertura de los Paralímpicos ha ido en aumento.

Por otro lado, se analizó el contenido de las notas dedicadas a Paralímpicos de Londres 2012, con el fin de determinar si el lenguaje se ajusta a los estándares establecidos. La Tabla № 2 resume los parámetros recogidos en la guía de estilo de Fernández (2006), ya que de los textos mencionados en este artículo que plantean sugerencias, se la considera más exhaustiva y apropiada para el estudio presente. La tabla también expone ejemplos de las mencionadas pautas.

Tabla $N^{\circ} 2$ Ejemplos de parámetros de términos inadecuados - adecuados

\begin{tabular}{|c|c|}
\hline INADECUADOS & ADECUADOS \\
\hline 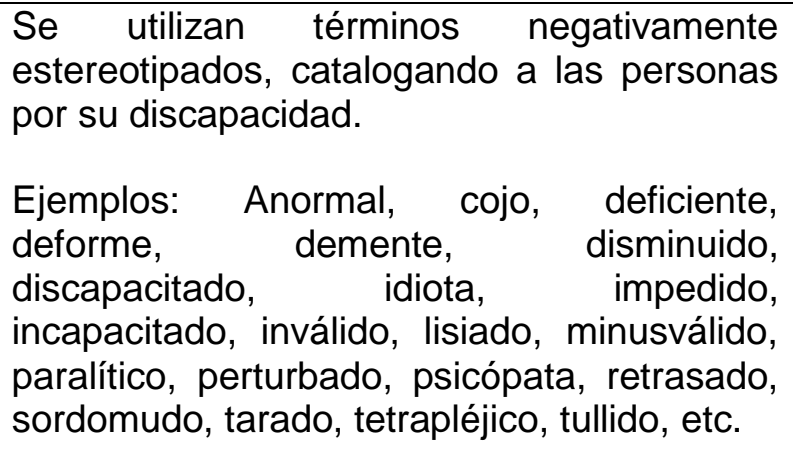 & $\begin{array}{l}\text { Se prioriza la condición de persona frente a } \\
\text { la discapacidad. } \\
\text { Ejemplos: Persona con discapacidad, } \\
\text { persona sorda o con deficiencia auditiva, } \\
\text { persona ciega, persona con Alzheimer, etc. }\end{array}$ \\
\hline $\begin{array}{l}\text { Se utilizan verbos con fuerte carga negativa. } \\
\text { Ejemplos: sufrir, padecer, afligido por, } \\
\text { víctima de, postrado. }\end{array}$ & $\begin{array}{l}\text { Se utilizan verbos neutros, que no suponen } \\
\text { una carga negativa. } \\
\text { Ejemplos: tener, utilizar, estar, etc. }\end{array}$ \\
\hline $\begin{array}{l}\text { Se centra en la discapacidad o en la } \\
\text { polémica. }\end{array}$ & Se enfoca en la persona. \\
\hline
\end{tabular}

\section{Elaboración propia en base a la Guía de Estilo sobre Discapacidad para Profesionales de los Medios de Comunicación (Fernández, 2006).}


Para delimitar la muestra de estudio de los dos periódicos impresos, se utilizó la base de datos de Lexis Nexis Academic, además de las hemerotecas del Marca (Orbyt) y El País (Kiosko y Más). Se analizaron las noticias publicadas en las versiones impresas de los periódicos en las siguientes fechas: del 27 de julio al 13 de agosto del 2012 (Olímpicos) y del 29 de agosto al 10 de setiembre del 2012 (Paralímpicos).

Para las noticias de El País se empleó el término "olímpicos" en el campo de búsqueda de Lexis Nexis Academic, con lo que se obtuvieron más de 600 resultados. Suprimiendo las noticias duplicadas, esta búsqueda generó 334 resultados. Para identificar las noticias relacionadas a los Paralímpicos, del 29 de agosto al 10 de setiembre del 2012, se introdujo en la base de datos el término "paralímpicos" delimitando nuevamente las fechas. Se obtuvo un resultado de 60 notas, y luego de filtrar las noticias repetidas, se generaron 47 resultados. Sin embargo, se observó que la mayor parte de esta búsqueda mostraba notas de la agenda televisiva (programación). Al seleccionar manualmente las noticias que cubrían los Juegos Paralímpicos se identificaron solo cuatro noticias.

Para el caso del Marca, se debió realizar un conteo manual de las noticias. Se incluyeron las notas que contaban con los siguientes elementos: titular, firma, cuerpo; quedando excluidos los espacios otorgados para programación o agenda, tablas de medalleros y tablas de resultados. Las infografías que contenían su propio titular y cuerpo fueron contadas como una nota aparte, diferenciando de las infografías que formaban parte de otra noticia, cuyos textos fueron analizados como parte de la noticia. También se excluyeron las informaciones que mencionaban a uno de los eventos pero su contenido no era específico sobre el evento. Para los Olímpicos se contaron 856 notas mientras que para los Paralímpicos se identificaron 69 notas.

En el caso de la Agencia EFE, para definir la muestra de estudio se utilizó la herramienta electrónica de EFE Data, una base de datos de la Agencia EFE que recoge toda la información publicada por este medio. Para los Juegos Olímpicos se utilizó el término "Londres 2012" en el campo de título, ya que esta fue la guía utilizada por la agencia para catalogar la cobertura de los Olímpicos, en el campo texto se introdujo el término "Olímpicos" y se delimitaron las fechas. Esta búsqueda generó 2.744 resultados. Se excluyeron las notas que fueron luego corregidas (10), los medalleros (16), los urgentes (12), los avances (86), los que trataban los Olímpicos de Río 2016 (1) y los que referían a la programación (22), dando como resultado 2.597 notas.

Para la búsqueda de la cobertura de Paralímpicos, se utilizó el término "Paralímpicos" en el campo de texto, delimitando las fechas. Esta búsqueda generó un total de 285 resultados. Se eliminaron las noticias que no tenían relación con los Juegos Paralímpicos de Londres 2012 y se obtuvo un resultado de 172 notas. Se empleó un método similar para contar las notas publicadas en los anteriores tres Paralímpicos, delimitando las fechas de Pekín 2008 (del 6 al 17 de setiembre), Atenas 2004 (del 17 al 28 de setiembre) y Sídney 2000 (del 18 al 29 de octubre). 
Inicialmente se consideraron 15 variables para el estudio y después de realizar un pretest (sobre el 10 por ciento de la muestra de Marca y la Agencia EFE, y el 100 por ciento de la muestra de El País), se resolvió analizar 13 variables, de las cuales solo se reflejarán en este trabajo las que mejor definen el planteamiento de la investigación.

El primer grupo de variables compara la importancia que dieron los medios de prensa a los Juegos Olímpicos de Londres 2012 con la cobertura otorgada a los Paralímpicos del mismo periodo. Se utilizaron las siguientes variables: número de noticias publicadas sobre el evento durante su duración y si el evento fue destacado en la portada del periódico. Para la variable que refiere a la portada solo se analizarán los medios con versión impresa: El País y Marca.

El segundo grupo profundiza el análisis de la cobertura otorgada a los Juegos Paralímpicos de Londres 2012. Se analizan los términos que describen la discapacidad, utilizando los parámetros resumidos en la Tablas $\mathrm{N}^{\circ} 2$, y en base a los patrones establecidos en la mencionada guía publicada por Fernández (2006), Guía de Estilo sobre Discapacidad para Profesionales de los Medios de Comunicación, del Ministerio de Trabajo y Asuntos Sociales, Real Patronato sobre Discapacidad.

En segundo lugar, se analizan los verbos que describen la discapacidad, determinando si los mismos son negativos (inadecuados) o neutros (adecuados), de acuerdo a la guía de estilo de Fernández (2006) y a los ejemplos resumidos en la Tabla $\mathrm{N}^{\circ} 2$. El elemento central mencionado en el titular y el lead determina si la noticia se enfoca en el evento deportivo o en los Juegos en general, si se enfoca en la discapacidad o en la historia de superación, o si el enfoque se centra en la polémica. Por último se verificó si la foto publicada con la noticia enfoca a la persona o a la discapacidad.

\section{Resultados de la investigación}

Del 27 de julio al 13 de agosto del 2012, El País publicó 334 notas sobre los Juegos Olímpicos de Londres. En las mismas fechas, Marca dedicó a los Juegos 820 notas mientras que la Agencia EFE divulgó 2.613 notas (Gráfico № 1). El total publicado es de 3.767 noticias o un promedio de 209 noticias por día.

Del 29 de agosto al 11 de setiembre del 2012 El País dedicó 4 noticias de los Juegos. Marca publicó 69 notas y la Agencia EFE divulgó 172 notas. El total publicado es de 245 notas, dando un promedio de 16 notas por día. 


\section{Gráfico $\mathrm{N}^{\circ}$ 1: Número de notas}

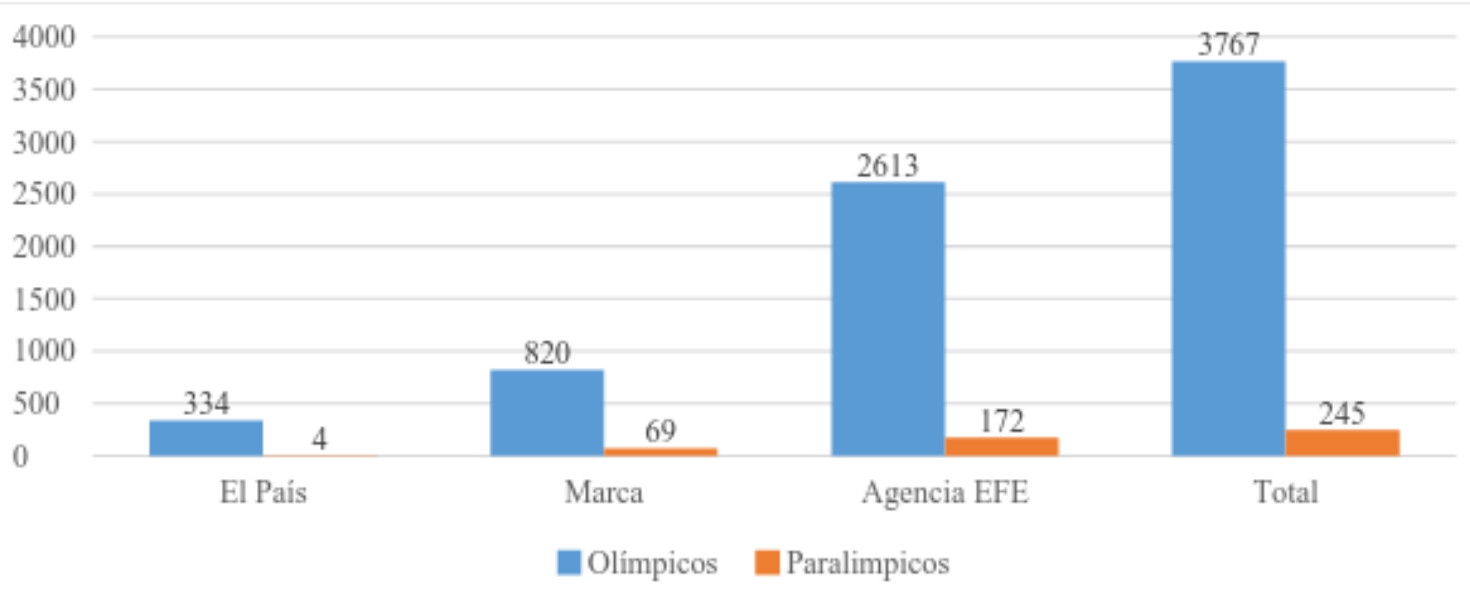

Si bien es cierto que en los Olímpicos participaron poco más del doble de número de atletas (véase Tabla № 1), la cobertura otorgada a los Paralímpicos no es proporcional. Los medios publicaron 0.36 notas por atleta olímpico mientras que dedicaron 0.06 notas por atleta paralímpico, por lo que se puede concluir que el bajo nivel de cobertura no es proporcional al número de atletas que participan en cada competencia.

De los 18 días de duración de los Juegos Olímpicos, el tema apareció en portada 18 veces (el 100 por ciento) en los periódicos de Marca y El País. Por otro lado, de los 14 días de Paralímpicos, el tema no apareció en portada ni una sola vez en El País y solo seis veces en Marca (el 43 por ciento).

El aumento del interés mediático de parte de la Agencia EFE por los Juegos Paralímpicos se evidencia en el Gráfico № 2. Para Sídney 2000, la agencia de noticias divulgó solo 6 notas, mientras que para Atenas 2004, este número alcanzó a 79 noticias. El pico de producción llegó en Pekín 2008, cuando la Agencia EFE publicó 174 notas.

\section{Gráfico $\mathbf{N}^{\circ}$ 2: Cobertura de Paralímpicos}

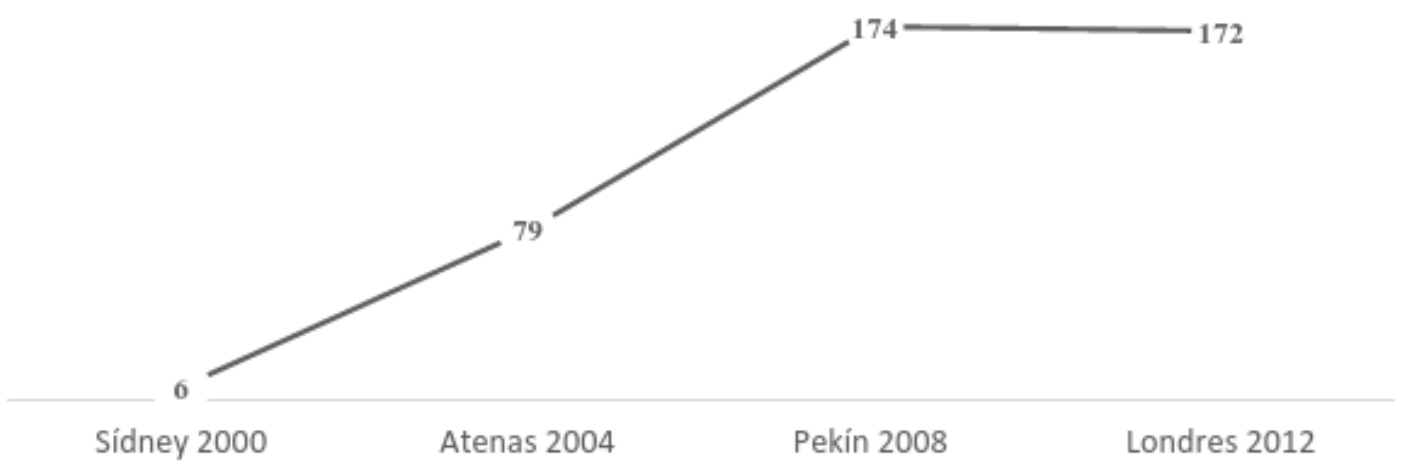

En cuanto al análisis de las notas dedicadas a los Paralímpicos de Londres 2012, la mayoría (69 por ciento) fueron notas pequeñas de menos de 300 palabras, mientras que el 16 por ciento fueron notas medianas. Solo el 15 por 
ciento fueron notas de más de 600 palabras, como se observa en el Gráfico № 3. Estos datos revelan que además de un escaso número de notas publicadas, estas han sido en general de tamaño pequeño. Al mostrar la variable por medio de prensa, se observa que Marca fue el que publicó el mayor porcentaje (26 por ciento) de noticias de más de 600 palabras.

\section{Gráfico N³: Tamaño de las noticias}

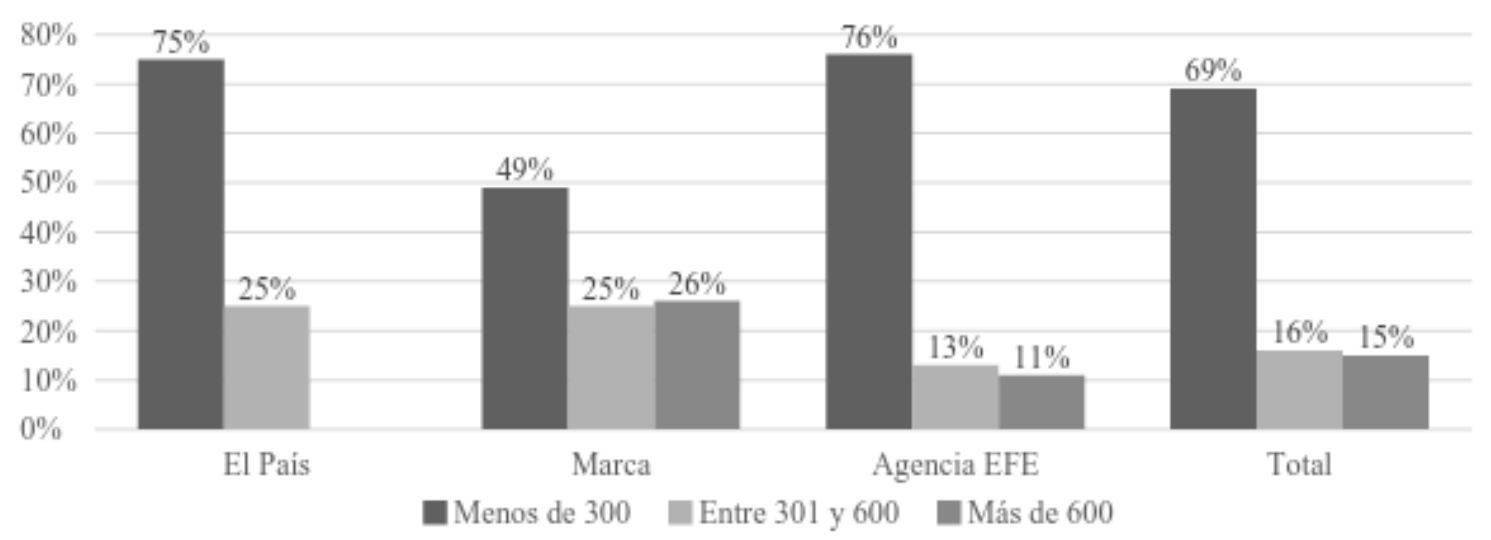

recogen ias intormaciones que sı mencionaron ia aıscapacidaa, un total de y4, apreciándose que en el 35 por ciento de los casos se utilizaron términos inadecuados, mientras que en el 65 por ciento utilizó términos adecuados. En el caso de la Agencia EFE, de las 48 notas que mencionaron la discapacidad, solo el 25 por ciento utilizó términos inadecuados. De las 45 noticias de Marca donde se mencionan la discapacidad, el 44 por ciento utilizó términos inadecuados.

\section{Gráfico № 4: Análisis de Términos}

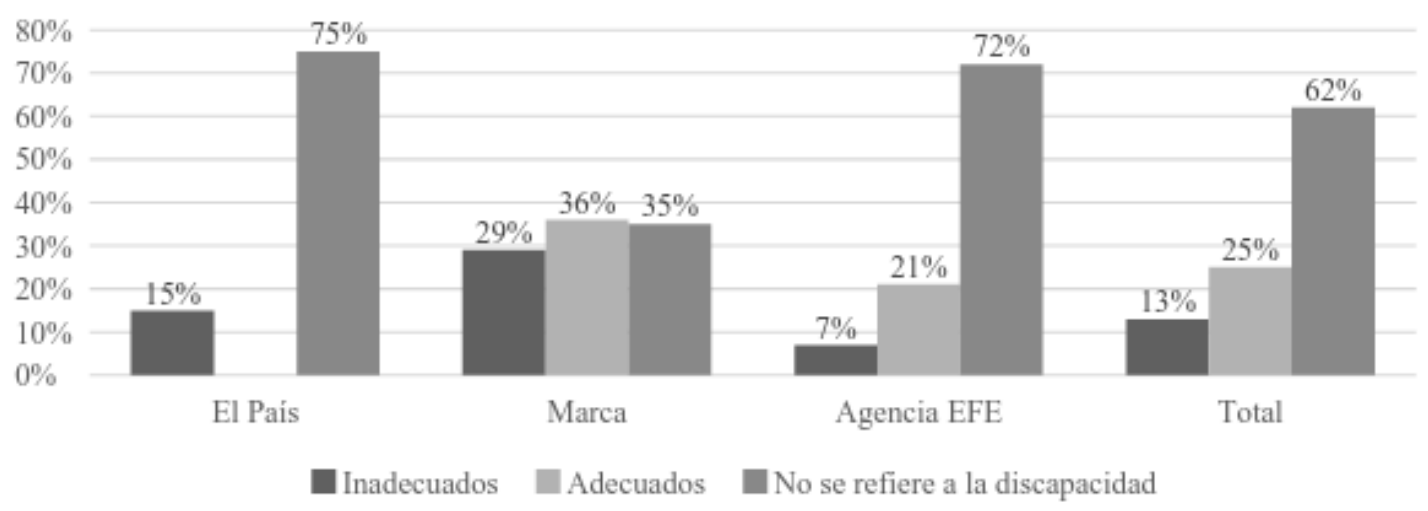




\section{Gráfico $\mathbf{N}^{\circ}$ 5: Noticias que mencionan la discapacidad}

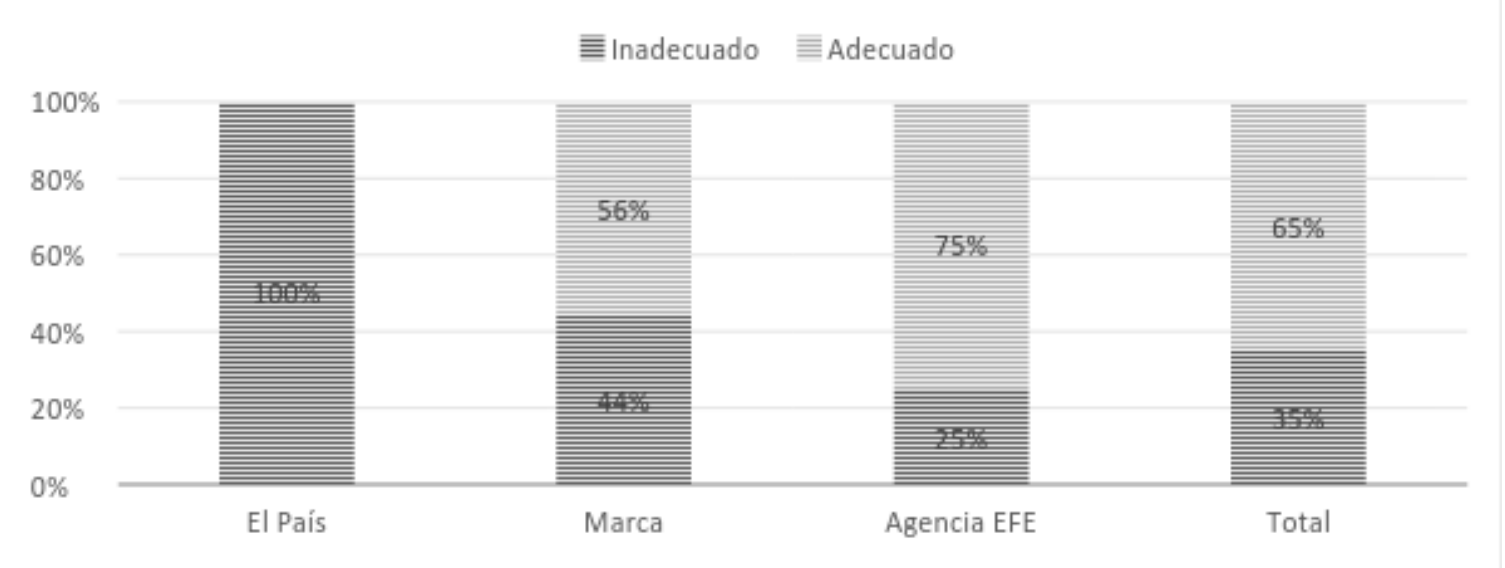

En el 77 por ciento de las notas analizadas no se utilizan verbos para referirse a la discapacidad, como se puede contemplar en el Gráfico № 6. En el Gráfico $N^{\circ} 7$ se ilustra cuando sí se utilizan verbos (en el 23 por ciento de los casos), en el 69 por ciento de ellos fueron adecuados mientras que el 31 por ciento de las veces se utilizaron verbos inadecuados como "padece" o "sufre" de alguna discapacidad o está "postrado" en una silla de ruedas.

\section{Gráfico $\mathbf{N}^{\circ}$ 6: Análisis de verbos}

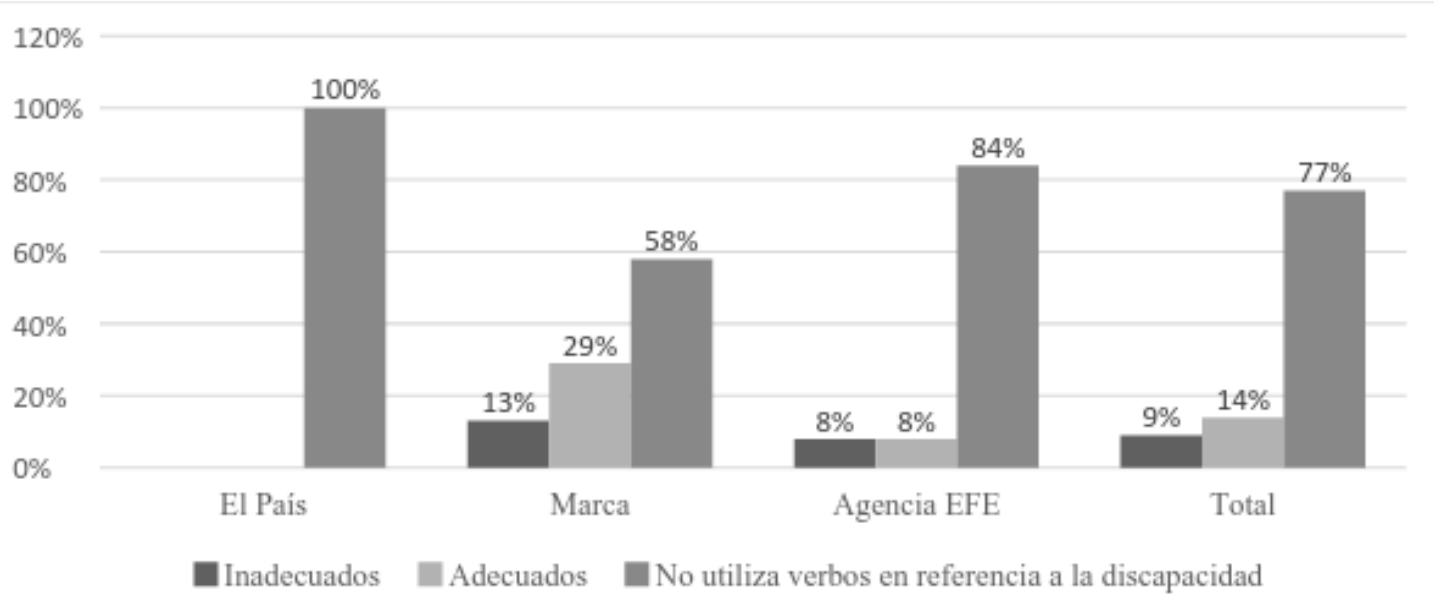




\section{Gráfico № 7: Verbos que mencionan la discapacidad}

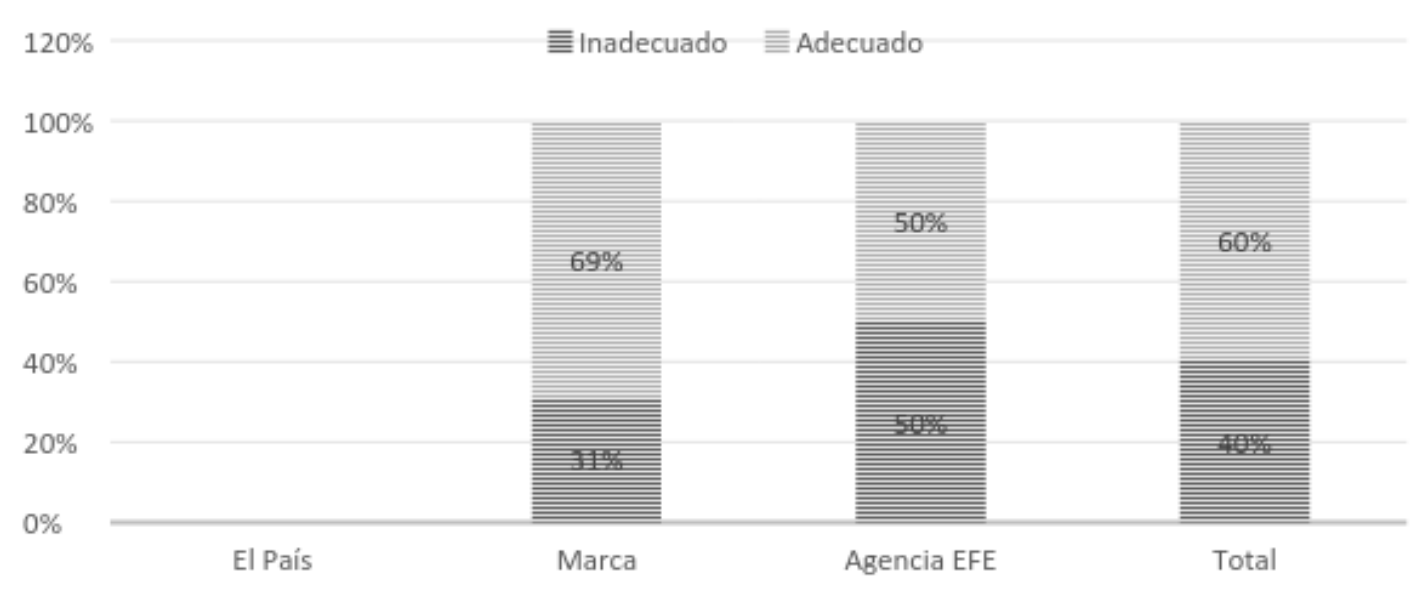

En el Gráfico № 8 se aprecia que el 86 por ciento de los casos se centra en el deporte o aspectos del mismo, mientras que el 10 por ciento lo hace en la discapacidad o la historia de superación del deportista. Solo el 4 por ciento de las noticias fueron dedicadas a polémicas.

En el caso de la Agencia EFE, casi el total de las noticias se referían únicamente a elementos del deporte (el 95 por ciento). En Marca, el 65 por ciento se enfocaban en el deporte mientras que el 29 por ciento - el mayor porcentaje de los tres medios - lo hacía en la discapacidad o en la historia de superación del atleta.

\section{Gráfico N 8: Enfoque de noticias}

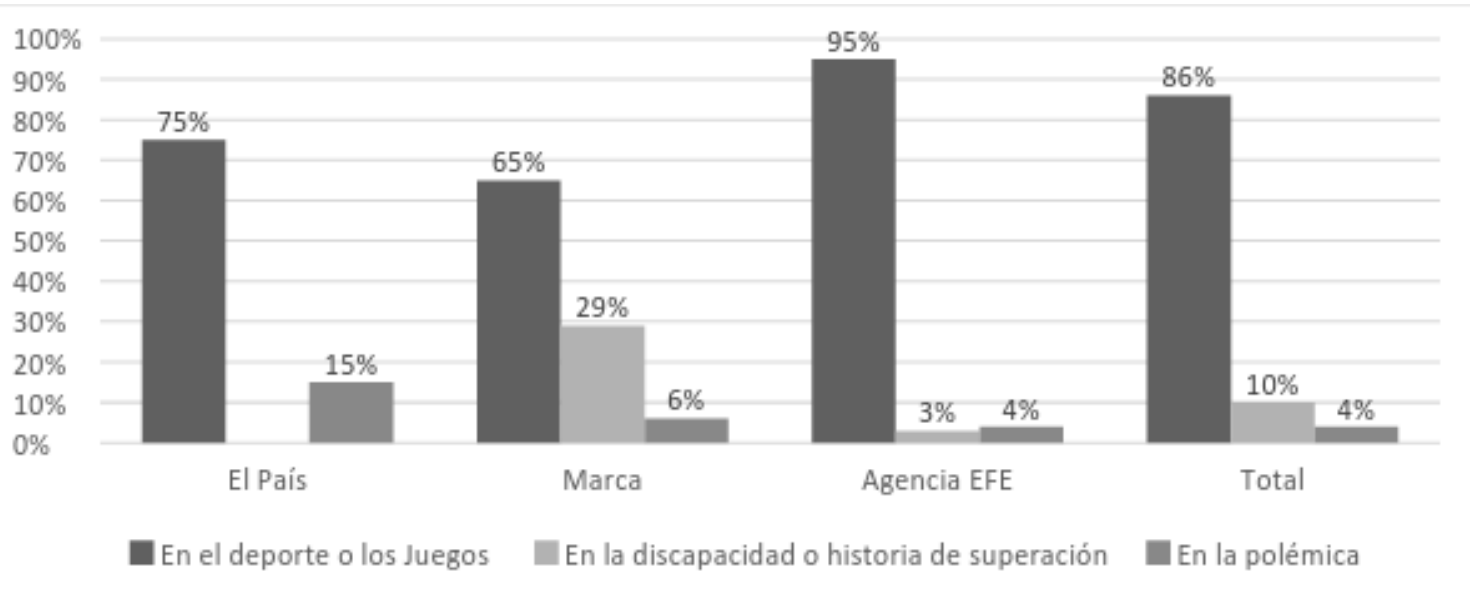

\section{Discusión}

La invisibilidad de las personas con discapacidad se evidencia en el nivel de cobertura que reciben los Juegos Paralímpicos en comparación con los Juegos Olímpicos, siendo de especial mención la cobertura realizada por El País, que solo dedicó cuatro noticias a los Juegos, con una visibilidad de menos de 300 
palabras cada una de ellas. Estos resultados concuerdan con otros estudios similares vinculados a diversos aspectos de la discapacidad (Golden, 2003; Tynedal et al., 2013; Solves, 2012).

La presencia en portada es una variable indicativa de la importancia que otorga un medio de prensa a determinado tema. Si bien para el caso de los Olímpicos, en los medios impresos de Marca y El País aparecieron en portada durante todos los días de la duración del evento, mientras que en Marca los Paralímpicos tuvieron presencia en menos de la mitad de los días y ninguna en El País.

Considerando la historia reciente de los Paralímpicos, parte del resultado es predecible y cabe destacar que el interés mediático ha ido en aumento de manera significativa. La Agencia EFE ha aumentado su cobertura de estos Juegos, de 6 notas dedicadas a los Paralímpicos de Atenas 2000 a 172 notas dedicadas a los Juegos de Londres 2012.

Al aumento del interés mediático se suma el lenguaje utilizado en las notas dedicadas a los Paralímpicos, los periodistas reconocen la importancia del lenguaje en la construcción de una visión del mundo que nos rodea (Declaración de Salamanca, 2004). Es por esto que se considera positivo, pese a que no contraste nuestra segunda hipótesis, el hecho de que la mayoría de las notas analizadas emplean lenguaje adecuado para referirse a los atletas con discapacidad.

Sin embargo, es necesario mencionar que los porcentajes de términos inadecuados, en los casos que sí se menciona la discapacidad, siguen siendo altos. Por ello, este estudio podría resultar útil como pauta para las organizaciones gubernamentales y no gubernamentales que trabajan por los derechos de las personas con discapacidad. Así como a que los medios de prensa renueven su compromiso por promover un lenguaje más inclusivo.

En cuanto al análisis de términos empleados, el enfoque de las noticias también es destacable, la mayoría de las mismas se centran aspectos del deporte, lo que promueve una visión normalizadora de la discapacidad.

\section{Conclusiones}

La discapacidad en la prensa tiene aún poca visibilidad proporcional en el ámbito del deporte pese a que el tiempo, junto con los esfuerzos del comité olímpico y paralímpico, sumado a una pequeña - y aspirante mayor concienciación - por parte de los medios de comunicación corrobora que "hoy es más visible que ayer". Los resultados de este estudio confirman la primera de las hipótesis en la que se refleja que la cobertura dedicada a los Paralímpicos de Londres 2012 ha sido escasa, en comparación con los Olímpicos. Sin embargo, el interés mediático por los Juegos ha ido en aumento a medida que se celebran nuevas ediciones de los mismos. Igualmente y como era de esperar, la prensa especializada como Marca dedicó proporcionalmente mayor cobertura al evento que El País y con informaciones más amplias, al 
igual que ya reflejaran otros estudios centrados en los paralímpicos del 2008 (Rius y Sanchis, 2010).

Los resultados del análisis de lenguaje resultan más esperanzadores y no confirman la segunda hipótesis ya que la mayoría de los términos y verbos utilizados, así como el enfoque de las noticias, fueron adecuados frente a una propuesta inicial negativa. Es importante señalar que esta investigación se ha realizado en prensa escrita, excluyendo otros medios de comunicación, como puedan ser los audiovisuales, que también son formadores de opinión y que quizá podrían aportar unos resultados diferentes. En esta dirección, investigaciones centradas en las imágenes de televisión como la de Sánchez y Mercado (2011) concluyen con resultados similares a los expuestos en este trabajo, no observan imágenes estereotipadas de la figura de los deportistas como en su día sí reflejaran otros estudios (Pappous et al, 2009).

La suma de estos resultados nos lleva a considerar que si bien el interés mediático que reciben los Paralímpicos no es mucho en la agenda informativa, va en aumento y en la senda correcta en cuanto al uso del lenguaje, pese a que aún quede mucho camino por recorrer. Sería conveniente plantearse la función de integración social de los medios por su papel a la hora de introducir, en la competición deportiva, la discapacidad con una mayor presencia. Un mayor compromiso periodístico, expresándose en una mayor cobertura en la agenda los Juegos Paralímpicos, podría contribuir muy positivamente a un establecimiento de agenda (McCombs, 2004), integradora entre la realidad y la opinión pública.

Igualmente es necesario que las organizaciones de deportes adaptados junto con los medios de comunicación entren en contacto con lazos más fuertes y renueven su compromiso con la sociedad de aumentar la cobertura de este tipo de iniciativas (Leardy, 2011). La presunta falta de interés de la prensa en los Paralímpicos es una problemática que merece estudios futuros que aspiren a conocer las causas desde las redacciones de los profesionales de la información, entre otros factores.

\section{Referencias}

Agencia Global de Noticias (2010). Medios de Comunicación y Discapacidad: Un aporte para la cobertura periodística sobre inclusión social. Asunción: Global Infancia. Disponible en http://www.globalinfancia.org.py/agenciaglobal/pdfs/medios-discapacidad.pdf. Recuperado el 28 de julio de 2015.

Álvarez, Angels y Mercado Maite (2015). La representación mediática del deportista con discapacidad en el reportaje televisivo. Informe Semanal, un estudio de caso. Revista Mediterránea de Comunicación: Mediterranean Journal of Communication 6.1 (2015), pp. 27-43.

Biklen, Douglas y Bogdan, Robert (1977). Media portrayals of disabled people: a study in stereotypes, Interracial Books for Children Bulletin. 8 (6y7), pp. 4-9 
Chevalley, Anne (2011). ¿Qué sabes de los Juegos Olímpicos? (3ª edición). Lausana: Museo Olímpico de Lausana Servicio. Comité Olímpico Internacional.

Cohen, Bernad (1963). The press and foreign policy. Princeton, NJ: Princeton University Press.

Comité Paralímpico Internacional -CPI- (2012a). History of the Paralympic Movement. http://www.paralympic.org/sites/default/files/document/120209103536284 2012 02 history+of+paralympic+movement.pdf. Recuperado el 28 de abril de 2015.

Comité Paralímpico Internacional -CPI- (2012b). Annual Report 2012. Disponible http://www.paralympic.org/sites/default/files/document/130710121410906 web ipc 13 annualreport 2012 final.pdf. Recuperado el 25 de abril de 2015.

Day, Louis (2002). Ethics in Media Communications: Cases and Controversies, $4^{\text {nd }}$ edition. Belmont, CA: Wadsworth, Thomson Learning.

Dearing, James y Rogers, Everett (1996). Agenda-setting. Thousand Oaks. CA: Sage.

Declaración de Madrid (2002), "NO DISCRIMINACIÓN MÁS ACCIÓN POSITIVA ES IGUAL A INCLUSIÓN SOCIAL". Congreso Europeo de personas con Discapacidad. Ministerio de Trabajo y Asuntos Sociales. Disponible en http://www.ub.edu/integracio/docs/normativa/internacional/DeclaracioMadrid.pdf. Recuperado el 8 de abril de 2015.

Declaración de Salamanca (2004), I Encuentro Sobre Periodismo y Discapacidad. Ministerio de Trabajo y Asuntos Sociales. Disponible en http://lenguajeadministrativo.com/wp-content/uploads/2012/12/declaracic3b3nde-salamanca-2004.pdf. Recuperado el 5 de mayo de 2015.

Del Río, Pablo (1986). La imagen de personas con deficiencias y el papel de los medios de comunicación. Real Patronato sobre Discapacidad: Madrid.

Fernández, José Luis (2006). Guía de estilo sobre discapacidad para profesionales de los medios de comunicación. Madrid: Ministerio de Trabajo y Asuntos Sociales. Real Patronato sobre Discapacidad.

Ferrara, Kate; Burns, Jan y Mills, Hayley (2015). Public attitudes toward people with intellectual disabilities after viewing olympic or paralympic performance. Adapted Activity Physical Quarterly. 32 (1), pp. 19-33.

Golden, Anne (2003). An Analysis of the Dissimilar Coverage of the 2002 Olympics and Paralympics: Frenzied Pack Journalism versus the Empty Press Room. Studies Quarterly. Summer/Fall, 23 (3/4).

Instituto Nacional de Estadística -INE- (2009). Panorámica de la discapacidad en España: Encuesta de Discapacidad. Autonomía personal y situaciones de Dependencia 2008. Cifras INE. Boletín Informativo $N^{\circ} 10$. Disponibles en: http://www.ine.es/revistas/cifraine/1009.pdf. Recuperado el 5 de abril de 2015. 
lyengar, Shanto y Kinder, Donald (1987). News that matter: Television and American Opinion. Chicago: University of Chicago Press.

Krane, Meghan (2010). The socially filtered media agenda: a study of AgendaSetting among news outlets on Twitter. Columbia: University of Missouri.

Leardy, Luis (2011). La importancia de los medios de comunicación en la visibilidad del deporte de personas con discapacidad. $3^{\underline{a}}$ Conferencia Nacional de Deporte Adaptado. La integración en el contexto internacional, 22-23 de febrero. Disponible en: http://www.csd.gob.es/csd/estaticos/dep-adp/conda2/10Luis-Leardy.pdf Recuperado el 28 de julio de 2015.

López-Escobar, Esteban; Llamas, Juan Pablo y McCombs, Maxwell (1996). Una dimensión social de los efectos de los medios de difusión: agenda-setting y consenso. Comunicación y Sociedad. Vol. IX n 1 y 2, pp. 91-125.

Marques, Renato; Gutierrez, Gustavo; Bettine, Marco; Nunomura, Myriam y Pombo, Rafael (2014). Media approach to paralympic sports: Brazilian athletes' standpoint. Movimento, 20 (3), pp. 989-1015.

McCombs, Maxwell (2004). Setting the agenda: The mass media and public opinion. Cambridge: Polity Press.

McCombs, Maxwell (1996). Influencia de las noticias sobre nuestras imágenes del mundo. En Bryant, J. y Zillmann, D. (1996), (v.o. 1994)). Los efectos de los medios de comunicación. Investigaciones y teorías. Barcelona: Paidós.

McCombs, Maxwell y Shaw, Donald (1972). The Agenda-Setting Function of Mass Media. The Public Opinion Quarterly. Vol. 36, No. 2, pp. 176-187.

Nelson, Jack (1996). The Invisible Cultural Group: Images of Disability. En Paul Lester (Ed.). Images That Injure: Pictorial Stereotypes in the Media. Westport, CT: Praeger.

Organización de Naciones Unidas -ONU- (1988). Programa de Acción Mundial para las Personas con Discapacidad. Documento A/37/51 aprobado por la Asamblea General por Resolución 37/52. Madrid: Real Patronato de Prevención y de Atención a Personas con Minusvalía. Disponible en http://www.siis.net/docs/ficheros/24112 Programa\%20de\%20accion\%20mundi al\%20para\%20las\%20personas.pdf. Recuperado el 25 de julio de 2015.

Organización Mundial de la Salud -OMS- (2011). World Report on Disability. Disponible en http://www.who.int/disabilities/world report/2011/report/en/ Recuperado el 25 de junio de 2015.

Pappous, Atthanasios; Marcellini, Anne y Léséleuc, Eric (2009). La representación mediática del deporte adaptado a la discapacidad en los medios de comunicación. Agora para la educación física y el deporte 9, pp. 31-42.

Paradis, Kyle; Misener, Laura; Rich, Kyle; McPherson, Gayle; McGillivray, David y Legg, David (2014). Separate but equal? An assessment of awareness 
and attitudes toward disability and para sport at the 2014 Commonwealth Games. Journal of Exercise, Movement, and Sport, 46 (1).

Rius, Inmaculada y Solves, Josep (2010). Discapacidad y comunicación: periodismo especializado para públicos diversos. Comunicación y hombre: revista interdisciplinar de ciencias de la comunicación y humanidades 6, pp. 165-176.

Rodríguez, Raquel (2004). Teoría de la Agenda-Setting aplicación a la enseñanza universitaria. Alicante: Observatorio Europeo de Tendencias Sociales, Universidad de Alicante.

Rubio, Raquel (2014). Twitter y la teoría de la Agenda-Setting: mensajes de la opinión pública digital. Estudios sobre el Mensaje Periodístico. Vol. 20, Núm. 1 (Enero - Junio), pp. 249264.

Sánchez, Sebastián y Mercado, Maite (2011). Narrativa audiovisual y discapacidad: realización televisiva comparada de los juegos olímpicos y paralímpicos de Pekín 2008. Zer: Revista de estudios de comunicación, pp. 89107.

Solves, Josep (Coord.) (2012), Tratamiento de los Juegos Paralímpicos de 2008 en los medios españoles. Madrid: Comité Español de Representantes de Personas con Discapacidad (CERMI).

Solves, Josep (2013), SOS Discapacidad: los discursos de la discapacidad en los medios españoles. Discurso \& Sociedad. Vol. 7 (1), pp. 49-72.

Tynedal, Jeremy y Wolbring, Gregor (2013). Paralympics and its athletes through the lens of the New York Times. Sports. 1 (1), pp. 13-36. 